\title{
ABUNDANCES IN STARS IN GLOBULAR CLUSTERS FROM PALOMAR CCD SPECTRA
}

\author{
E. Myckki Leep and George Wallerstein \\ University of Washington
}

J. B. Oke

California Institute of Technology

We have completed abundance analyses of stars in three globular clusters: M71, M4. and M22. Spectra of resolution 0.3 and 0.6 (two pixel) resolution have been obtained with the Palomar coudé spectrograph and a TI CCD. The analysis was carried out with model atmospheres and f-values derived from three sources: absolute f-values derived by theory for the 6300 line of OI and for CN bands. laboratory f-values for lines that are too weak in the sun to be useful, and solar f-values. The last introduce an uncertainty of about 0.25 dex because solar f-values derived via the Holweger-Muller model differ from those derived via the BEG.N model.

Resulting abundances of iron are as follows: for $M 71$, which is important as a calibrator of strong-lined globular clusters, we find that $[\mathrm{Fe} / \mathrm{H}]$ lies between -0.6 and -1.0 , depending on which model is used for solar f-values and which wavelength region is used. For $\mathrm{M4}$ we find $[\mathrm{Fe} / \mathrm{H}]$ to lie between -1.4 and -1.2 . which is similar to photometric determinations. For M22, which has been reported to be inhomogeneous in composition. we find star III-3 to be richer in iron by 0.25 dex. as compared to star IV-102. This difference is similar to prior findings and confirms a small inhomogeneity in M22.

For CNO abundances we find the following: in $\mathrm{M} / 1[\mathrm{O} / \mathrm{H}]=-0.6$. which becomes a range from 0.0 to +0.4 for $\left[\mathrm{O}_{/}^{\prime} \mathrm{Fe}\right.$. depending on the iron abundances. For $\mathrm{M} 4$ we did not observe oxygen, but Geisler (Ph.D. thesis. 1983) found $[\mathrm{O} / \mathrm{Fe}]$ $=+0.9$ from two stars in $\mathbf{M 4}$.

Our analysis of the 2-0 vibrational band of the red $\mathrm{CN}$ system yields a line in the $(\mathrm{C} / \mathrm{H}, \mathrm{N} / \mathrm{H})$ plane. A search for the $\lambda 8727$ line of $\mathrm{CI}$ in two clusters was not successful.

For Mi1 an analysis of $C N$ in three stars yields similar lines in the $(C / H$. $\mathrm{N} / \mathrm{H}$ ) plane, which can be understood if $\mathrm{C} / \mathrm{N}$ is between 1 and 3 . the main sequence values of $[\mathrm{C} / \mathrm{H}]$ and $[\mathrm{N} / \mathrm{H}]$ are near -1.0 . and the expected $\mathrm{CN}$ cycling and mixing have modestly increased $N$ at the expense of $C$.

For $\mathrm{M4}$ two stars also show reasonable lines in the $(\mathrm{C} / \mathrm{H} . \mathrm{N} / \mathrm{H})$ plane, provided that their initial values of $[\mathrm{C} / \mathrm{H}]$ and $[\mathrm{N} / \mathrm{H}]$ were about $\mathbf{- 1 . 2}$. 
For M22 there is a gross difference between the relatively metal-rich star III-3 and IV-102, with CN stronger in the former star by about a factor 10. This favors the idea that $\mathrm{C}$ and $\mathrm{N}$ follow's $\mathrm{Fe}$ and are all more abundant by about a factor of 3 in III-3, as compared with IV-102. In star III-3 we have detected the clump of ${ }^{13} \mathrm{CN}$ lines near $\lambda 8005$ and find a ratio of ${ }^{12} \mathrm{C} /{ }^{13} \mathrm{C}$ near 4 . At our resolution of only $0.6 \AA$ this is very uncertain, despite the signal-to-noise of about 150 . If correct, it indicates much deeper mixing than predicted by standard evolution and mixing theory.

Our results for various elements relative to iron are best shown in a table. We have rather little that is new for $\mathrm{M} 22$ and hence show relative abundances for the other two clusters in the following table.

TABLE I

$[\mathrm{X} / \mathrm{Fe}]$ for Various Elements

\begin{tabular}{|c|c|c|c|c|c|c|c|}
\hline Element & $M 71$ & $\begin{array}{l}\text { this } \\
\text { work }\end{array}$ & $\begin{array}{l}14 \\
\text { Geisler } \\
\text { Thesis }\end{array}$ & Element & $M 71$ & $\begin{array}{l}\text { this } \\
\text { work }\end{array}$ & $\begin{array}{l}\text { Geisler } \\
\text { Thesis }\end{array}$ \\
\hline $\begin{array}{l}\mathrm{O} \\
\mathrm{Na} \\
\mathrm{Mg} \\
\mathrm{Al} \\
\mathrm{Si} \\
\end{array}$ & $\begin{array}{l}+0.2 \\
+0.5 \\
+0.6 \\
+0.3\end{array}$ & $\begin{array}{l}+0.4 \\
+1.1 \\
+0.9 \\
+0.9\end{array}$ & $\begin{array}{l}+0.8 \\
+0.5 \\
+0.6 \\
+1.4 \\
+0.8\end{array}$ & $\begin{array}{l}\mathrm{Ca} \\
\mathrm{Sc} \\
\mathrm{Ti} \\
\text { Fe peak } \\
\text { s-process }\end{array}$ & $\begin{array}{l}+0.6 \\
+0.3 \\
+0.4\end{array}$ & $\begin{array}{l}+0.6 \\
+0.3\end{array}$ & $\begin{array}{c}+0.4 \\
+0.1 \\
+0.6 \\
+0.1 \\
0.0\end{array}$ \\
\hline
\end{tabular}

It is clear from the table that both clusters show a very substantial excess of the light metals relative to iron. The observed effect is noticeable for all the light elements, not just the integral-a nuclei and includes titanium. but not scandium. In $\mathrm{M4}$ the iron-peak elements go with iron, as do the four s-process elements observed by Geisler. We confirm his high sodium and aluminum abundances.

This research was supported by NSF Grant 84-15353 to G. Wallerstein and by NASA Grant NGL 05-002-134 to J. B. Oke. Computing time was granted by the National Center for Atmospheric Research. 